\section{In the Readers' Own Words How User Content in the Catalog Can Enhance Readers' Advisory Services}

\author{
Louise F. Spiteri and Jen Pecoskie
}

Louise F. Spiteri is Associate Professor School of Information Management, Dalhousie University, Halifax, Nova Scotia. Jen Pecoskie is an Independent researcher, based in London, Ontario. Canada.

Correspondence to this column should be addressed to Laurel Tarulli, Librarian and Information Services Manager, Sacred Heart School of Halifax; email: laureltarulli@yahoo.com.
It's always challenging and exciting to find topics for the readers' advisory column, and professionals willing to write for them! I've been so thankful to the many professionals who have so generously given their time and shared their expertise for this column. From lessons learned, case studies and differing opinions on RA and its future, it is amazing how various and rich this area of librarianship is - and how rewarding and frustrating! In an effort to continue to provide a broad spectrum of thoughts and ideas, I asked Dr. Louise Spiteri of Dalhousie University to write for this issue. Spiteri recently completed two stages of research examining subject headings and user-generated content and how these connect with RA access points. Jen Pecoskie was Spiteri's research partner in both studies.—Editor

I

n the public library context, readers' advisory (RA) services, which aim to provide the right book in the hands of the user at the right time, is a central and longstanding core of the profession. In traditional RA services, knowledgeable library staff help readers with their leisure-reading needs. In most public libraries, RA models are heavily based on the traditional reference-interview structure. The conversations start with a roving readers' advisor approaching a reader within the library, or a patron who approaches an RA staff member. The RA librarian generally has a list of predetermined questions that assists in deciding which books to suggest, and when the reader leaves, the conversation is documented by a statistic, with little or no feedback or follow-up with that patron. ${ }^{1}$ Reading preferences can be a very personal experience: Some readers may prefer accessing a readers' advisor remotely rather than face-to-face, or to only have a book conversation with other community members, rather than with library staff. Other readers might be reluctant to discuss their reading interests with librarians, possibly because of shyness, a lack of awareness that some librarians are trained to provide this type of service, a perception of librarians as authority figures, assumptions that a librarian of a different age, gender, culture may not relate to them, and a fear of having their reading interests dismissed or judged. ${ }^{2}$

This paper discusses two research studies conducted to examine the contribution of user-generated content in the form of tags and reviews in public library catalogs to both the description of fiction titles as well as its possible extension to RA services. Social services such as Amazon (www.amazon .com), LibraryThing (www.librarything.com), and Goodreads (www.goodreads.com) have long encouraged readers to share their reviews of books, and, particularly in the case 


\section{READERS' ADVISORY}

of the latter two services, to contribute descriptive content to the titles in the form of tags. Various online public access catalogs are integrating social discovery platforms such as BiblioCommons (www.bibliocommons.com), SirsiDynix (www.sirsidynix.com), and Encore (http://encoreforlibraries .com/overview), which allow the contribution of this type of user content. This research was driven by the belief that these discovery systems could be used to encourage readers to comment on titles read, make recommendations for future reading based on such ideas as shared interests, and classify items in the catalog with their own tags or reviews that may be more reflective of their language and needs than the formal subject headings assigned by library staff. These tags and reviews can serve as added access points by which users can search for items of interest. Librarians and library staff can interact with users, learn more about their needs, and become part of the online community, while at the same time compile recommended reading lists and make purchasing decisions based on the reviews and recommendations made in the catalog by users.

\section{LITERATURE REVIEW}

In library cataloging practice, the description of the content of fiction titles can be problematic for a variety of reasons. Subject headings, normally derived from Library of Congress (LC), are assigned to bibliographic records for fiction titles to reflect a balanced and unbiased opinion about the content of these titles. The extent to which this neutrality is feasible is questionable, however. LC headings can reflect biases and assumptions that reflect certain sociopolitical or cultural norms. ${ }^{3}$ These headings may not change quickly enough to match the language and culture of readers, as well as new literary genres. Many readers consult social sites like Goodreads and Amazon to find materials to read, quite possibly because user reviews provide them with more useful and honest assessments of not only the content of the titles, but also their quality. ${ }^{4}$ Neutrality of content description might thus not be the ideal scenario for readers.

In their analysis of 648 bibliographic records derived from six sources (two online bookstores, two RA databases, and two public library catalogs), Adkins and Bossaller found that the online bookstores and RA databases were more likely to use fiction access points than library catalogs. The authors concluded that the library catalog records, where greater subject access is provided for nonfiction titles in the form of subject headings and classification numbers, may provide fewer access points than those records that contain user-generated content. ${ }^{5}$

Library catalog records are not particularly good at describing the effect of a fiction title, that is, its tone, its emotional impact on the reader, and the memories or associations that it can invoke in readers. The importance of providing access to effect has been emphasized by Wyatt, who suggests that fiction works should be classified by feeling rather than subject. ${ }^{6}$ Saarti distinguishes two elements found in fictional works, the factual and the imaginative. ${ }^{7}$ Beard and Thi-Beard advocate for focusing on why people read and to revise RA strategies to take this reasoning into account. ${ }^{8}$ When discussing affect, Dali found "readers do not differentiate between intangible/abstract (e.g., mood, atmosphere, tone) and concrete/objective (e.g., genre, subject) characteristics of books." ${ }^{\prime 9}$ Naik points to how readers in Goodreads readership communities use appeal terms in an organic manner; this offers the opportunity to broaden the definition of RA as informal advisory roles that can be undertaken successfully by other readers. ${ }^{10}$ Mikkonen and Vakkari found that "current library systems can be considered somewhat static as they do not adapt to meet the needs of different readers," and that faceted search interfaces are a strategy that could help. ${ }^{11}$ Similarly, Šauperl's discussion of fiction description indicates that genre characteristics, and positive and negatives reviews, are essential to bolster the information in subject description provided by librarians. ${ }^{12}$

\section{STUDY 1: METHOD}

Both studies examined the same dataset, which was obtained from libraries selected using the Canadian Public Libraries Gateway (www.collectionscanada.gc.ca/gateway/s22-200-e .html) and provided a listing of all public libraries in Canada of all types and sizes. The entire population of Canadian public libraries $(N=43)$ with the most commonly used social discovery platforms was included: BiblioCommons $(n=33)$, SirsiDynix $(n=3)$, and Encore $(n=7)$. From the final set of library-located bibliographic records $(N=831)$, the bibliographic records for 22 unique adult fiction titles were examined in the 43 social discovery platforms. The 22 titles were selected from a variety of shortlists and winning lists of major literary prizes. In total, 4,541 tags, 3,501 LC Subject Headings, and 631 reviews were extracted from the base sample of 831 records originating from the 22 titles. The goals of the first study were to examine the kind of content readers contribute about adult fiction titles; the categories of access points that readers provide about the content of adult fiction titles, e.g., location, subject, and genre; and the extent to which user-contributed access points parallel those established for the traditional face-to-face RA model. ${ }^{13}$

Two researchers independently derived categories from the tags and subject headings from each record using the grounded theory method. ${ }^{14}$ Each researcher coded independently and inductively, allowing categories to emerge from the dataset. Similarly, two other researchers worked independently from each other to derive categories from the user reviews and comments. Derived categories provide information about the titles' content, for example, information about the location of a story (e.g., Nunavut), or the emotional impact of the title on the reader (e.g., boring, funny, etc.). In both cases, a third researcher, who was not involved in the first round of analysis, independently coded for categories for 
the tags, subject headings, and reviews. This third researcher subsequently assessed the three sets of categorical analyses of the tags, subject headings, and review data, and examined them for overlap, clarity, exclusivity, and relevance. These three sets of independent categories were assessed for similarity and subsequently grouped into one finalized set of categories

\section{STUDY 1: FINDINGS}

The study found that while user tags place a greater emphasis on the topic of a fiction title, or what could be called the subject of the work, the LC Subject Headings emphasize the genre of the fiction title rather than information about its content. The thematic emphasis of the user content indicates a clear distinction made between objectivity versus the affective impact of the fiction title. As stated previously, while catalogers want to provide an objective description of the subject of a title, readers want to add the added layers of emotional and reading experiences. Both user tags and reviews contained information pertaining to the tone of the titles, an area not covered by the LC Subject Headings. Tone is of particular interest, since this points to the ability of user content to reflect the affective aspects of a work, that is, the emotional impact on the user, the mood of a work, and so forth. Subject headings are not equipped to deal with affect, since emphasis is on describing the more neutral components of a work, such as locations, periods, and topics. Usergenerated metadata can serve to express important aspects of a fiction title that cannot always be expressed easily by LC Subject Headings. Where catalogers want an objective stance on what the title conveys, users want to provide a complete picture of the title, including its subject, its emotional impact, and their reading experience. User-generated metadata can thus serve to add valuable additional information to a bibliographic record about the affective or emotional impact of a fiction title. Tagging, in particular, allows for the broader expansion of a readership community, where the individual user, through those tag connections, may share reading interests with others. User-generated reviews allow for a similar level of expansion, since users can click on the associated username to see other titles, tags, and reviews with which this name is associated.

\section{STUDY 2: METHOD}

Because the first study did not analyze in-depth the nature of these affective access points, a second study conducted a comprehensive analysis of the affective content expressed in reader reviews contained in the dataset used in the first study. Specifically, this study examined the specific types of emotions expressed by readers; the tones elicited by the titles for the readers; and the associations to external factors readers make as part of their reading experience. The end goal of this analysis is to create useful taxonomies of emotions, moods, and associations that could be used to assist readers as they narrow the focus of their searches for works of fiction, either through facets supplied by the social discovery system layer on a library catalog (e.g., narrow the results by a specific types of emotions, such as sadness, joy, and so forth), or through interactions with readers' advisory staff. ${ }^{15}$

The second study used grounded theory once again to analyse the reviews, only this time, a deductive approach was used, whereby the content of the reviews was coded into three predetermined categories-emotions, tones, and associations-as these categories featured prominently in the findings of the first study. The deductive approach is appropriate when the objective of the study is to test existing theory or retest existing data in a new context. ${ }^{16}$ One of the co-authors and a research assistant independently coded the 631 user reviews, assigning a color per code as it related to one of the three categories of affect: red for emotions; blue for tones; and green for associations. The second co-author, who was not involved in the first round of analysis, independently coded the reviews according to the three categories, and subsequently assessed the three sets of categorical analyses of user reviews, examining them for overlap, clarity, exclusivity, and relevance. Taxonomies for emotions, tones, and associations were created by examining all concepts coded in the relevant colors and sorting the terms into basic-level categories (e.g., fear, sadness, love, and so forth). The taxonomies for emotions and associations were derived from an analysis of extant taxonomies in the fields of social psychology, cognitive science, and behavioural science. ${ }^{17}$ The taxonomy for tones was based on the analyses of the reviews in the first study.

\section{STUDY 2: FINDINGS}

The study revealed that readers expressed a rich variety of affective access points for the 22 fiction titles examined. Specifically, emotions were represented by 9 basic categories and 44 unique emotions, tones by 11 basic categories and 141 unique tones, and associations by 7 basic categories and 31 unique associations. The diversity with which users express their emotional states in the reviews points to the impact of user-generated metadata on the richness of the bibliographic record. The MARC record provides only the bare-bones description of the content of the title; the user reviews provide the added richness and nuances of the title that can help provide other readers with a greater understanding of the title and, perhaps more importantly, help them decide whether this is an item they would enjoy reading. Tone expresses the readers' perception of the intent of the title. People may have a set idea of the tone of a title they would like to read based on a variety of factors, such as the wish to match their existing mood (e.g., I am sad), past experiences with titles with a particular tone, or an emotional state they would like to achieve (e.g., I need cheering up). Associations express how 


\section{READERS' ADVISORY}

readers associate a title with related concepts, such as other titles, personal experiences and situations, other authors, and so forth. Knowledge of these associations can be very helpful in assisting readers to find related titles they can read.

\section{CONCLUSION}

The findings of these two studies provide insight into the kind of content that readers contribute in Canadian public library catalogs that allow such contributions. As has been shown, user-generated content serves to complement the traditional bibliographic record; while the latter provides greater emphasis on the genre and format of a fiction title, user content provides more insight into the subject of a title, its protagonists and, perhaps most importantly of all, its effect. User-generated reviews, in particular, provide a rich data set that clearly connects to RA access points and, as such, has possible implications for readers and RA professionals, as both of these parties can use them for RA-related decisions that are more informed and relevant to their pleasure reading and work, respectively.

RA staff could use reader-generated content, as well as the three taxonomies, to assist readers in selecting items to read or to generate suggested reading lists that correspond to these taxonomies (e.g., books that are imaginative and cerebral). The taxonomies can help readers define more clearly their reading experience and why they enjoy (or not) reading certain works. The ability to express these experiences can open up possibilities for reading referrals, both from other readers, as well as RA staff, and to help provide the right book in the hands of the user at the right time.

\section{References}

1. Laurel Tarulli and Louise F. Spiteri, "Library Catalogues of the Future: A Social Space and Collaborative Tool?" Library Trends 61, no. 1 (2012): 107-31.

2. Neil Hollands and Barry Trott, "Improving the Model for Interactive Readers' Advisory Service," Reference \& User Services Quarterly 45, no. 3 (2006): 205-12; Anne K. May et al., "A Look at Reader's Advisory Services," Library Journal 125, no. 15 (2000): 40-44; Kaite Mediatore Stover, "Stalking the Wild Appeal Factor," Reference \& User Services Quarterly 48, no. 3 (2009): 243-46; Barry Trott, "Advising Readers Online," Reference \& User Services Quarterly 44, no. 3 (2005): 210-15.

3. Steven A. Knowlton, "Three Decades Since Prejudices and Antipathies: A Study of Changes in the Library of Congress Subject Headings," Cataloging \& Classification Quarterly 40, no. 2 (2005): 123-45; Hope A. Olson, "How We Construct Subjects: A Feminist Analysis," Library Trends 56, no. 2 (2007): 509-41.

4. Kamy Ooi and Chern Li Liew, "Selecting Fiction as Part of Everyday Life Information Seeking," Journal of Documentation 67 , no. 5 (2011): 748-72.

5. Denice Adkins and Jenny E. Bossaller, "Fiction Access Points across Computer-Mediated Book Information Sources: A Comparison of Online Bookstores, Reader Advisory Databases, and Public Library Catalogs," Library \& Information Science Research 29 (2007): 354-68.
6. Neal Wyatt, "The Concept of Appeal Is on the Table, and Readers' Advisory Librarians Are Revolutionizing It," Library Journal, July 2007, 40-43.

7. Jarmo Saarti, "Fiction Indexing and the Development of Fiction Thesauri," Journal of Librarianship and Information Science 31, no. 2 (1999): 85-92

8. David Beard and Kate Vo Thi-Beard, "Rethinking the Book: New Theories for Readers' Advisory," Reference \& User Services Quarterly 47, no. 4 (2008): 331-35.

9. Keren Dali, "From Book Appeal to Reading Appeal: Redefining the Concept of Appeal in Readers' Advisory," The Library Quarterly: Information, Community, Policy 84, no. 1 (2014): 39-40.

10. Yesha Naik, "Finding Good Reads on Goodreads: Readers Take RA into Their Own Hands," Reference \& User Services Quarterly 51, no. 4 (2012): 319-23.

11. Anna Mikkonen and Pertti Vakkari, "Readers' Search Strategies for Accessing Books in Public Libraries," In Proceedings of the 4th Information Interaction in Context Symposium (New York: ACM, 2012), 222

12. Alenka Šauperl, "Four Views of a Novel: Characteristics of Novels as Described by Publishers, Librarians, Literary Theorists, and Readers," Cataloging \& Classification Quarterly 51, no. 6 (2013): 624-54.

13. Jen Pecoskie, Laurel Tarulli, and Louise F. Spiteri, "OPACs, Users, and Readers' Advisory: Exploring the Implication of User-Generated Content for Readers' Advisory in Canadian Public Libraries," Cataloging \& Classification Quarterly 52, no. 4 (2014): 431-53.

14. James Hollan, Edwin Hutchins, and David Kirsh, "Distributed Cognition: Toward a New Foundation for Human-Computer Interaction Research," ICM Transactions on Computer-Human Interaction 7, no. 2 (2000): 174-96; Anselm L. Strauss and Juliet M. Corbin, Basics of Qualitative Research: Grounded Theory Procedures and Techniques (Newbury Park, CA: Sage, 1998); Diane Walker and Florence Myrick, "Grounded Theory: An Exploration of Process and Procedure," Qualitative Health Research 16, no. 4 (2006): 547-59.

15. Louise F. Spiteri and Jen Pecoskie, "Affective Taxonomies of the Reading Experience: Using User-Generated Reviews for Readers' Advisory" (paper presented at the annual meeting for the American Society for Information Science and Technology, Copenhagen, Denmark, October 14-18, 2016).

16. Ji Young Cho and Eun-Hee Lee, "Reducing Confusion about Grounded Theory and Qualitative Content Analysis: Similarities and Differences," Qualitative Report 19, no. 64 (2014): 1-20.

17. Alan D. Baddeley, "The Psychology of Memory," in The Essential Handbook of Memory Disorders for Clinicians, edited by Alan D. Baddeley, Michael Kopelman, and Barbara A. Wilson (Chichester, England: Wiley, 2005): 1-13; Matteo Baldoni et al., "From Tags to Emotions: Ontology-Driven Sentiment Analysis in the Social Semantic Web," Intelligenza Artificiale 6, no. 1 (2012): 41-54; Roddy Cowie and Randolph R. Cornelius, "Describing the Emotional States that are Expressed in Speech," Speech Communication 40, no. 1 (2003): 5-32; Beverley Fehr and James A. Russell, "Concept of Emotion Viewed from a Prototype Perspective," Journal of Experimental Psychology: General 113, no. 3 (1984): 464-86; Virginia Francisco et al., "EmoTales: Creating a Corpus of Folk Tales with Emotional Annotations," Language Resources and Evaluation 46, no. 3 (2012): 431-481; David Manier and William Hirst, "A Cognitive Taxonomy of Collective Memories," in Cultural Memory Studies: An International and Interdisciplinary Handbook, edited by Astrid Erll and Ansgar Nünning (Berlin: Walter de Gruyter, 2008): 253-62; Luke Mastin, "Types of Memory," The Human Memory, accessed July 25, 2016, www.human-memory.net/types.html; W. Gerrod Parrott, "Ur-Emotions and your Emotions: Reconceptualizing Basic 
In the Readers' Own Words

Emotion," Emotion Review 2, no. 1 (2010): 14-21; Robert Plutchik, "A General Psycho Evolutionary Theory of Emotion," Theories of Emotion 1: 3-31; Klaus R. Scherer, "What are Emotions? And How Can They be Measured?" Social Science Information 44, no. 4 (2005): 695-729; Phillip Shaver et al., "Emotion Knowledge: Further Exploration of a Prototype Approach," Journal of Personality and Social Psychology 52, no. 6 (1987): 1061-86; Larry R. Squire, "Memory Systems of the Brain: A Brief History and Current Perspective," Neurobiology of Learning and Memory 82, no. 3 (2004): 171-77; Christine Storm and Tom Storm, "A Taxonomic Study of the Vocabulary of Emotions," Journal of Personality and Social Psychology 53, no. 4 (1987): 805-16. 